\title{
The Teaching Exploration on Practical Training of Pharmaceutical Service Skill inside the school for Higher Vocational Education*
}

\author{
Peng Sun, Guijie Li, Kai Zhu** \\ Department of Biological and Chemical Engineering, Chongqing University of Education, \\ Chongqing, 400067, China \\ email: lazhuyu2@163.com
}

Keywords: higher vocational education; major of pharmaceutical trading and management; pharmaceutical care skills; practical teaching

\begin{abstract}
At the background of the idea "Cooperation of colleges and enterprises, combination of work and study" in higher vocational education, increasing employment rate and enhancing students' professional capacity as well as comprehensive quality are important subjects of higher vocational talents training. The thesis introduces the major of pharmaceutical trading and management in a university in Chongqing developing the building of the teaching model that is "Practical training of pharmaceutical care skills inside the school" at the main line of five working processes on pharmacist job and offering some constructive suggestions to practical teaching of related majors.
\end{abstract}

\section{Introduction}

As community service system is continuously improving in our country, community will take on most public health-care works which needs to establish pharmaceutical care regarding patients as a center and rational drug use as a core [1]. Pharmacy professional education in the higher vocational school undertakes the responsibility of transporting talented people for community public health care work and needs to focus on cultivating students' practical operation ability. Therefore, our school has done a great many studies on how to improve students' practical operation skills, strengthen students' professional accomplishments and increase students' employment rate. We develop a teaching model of "Practical training of pharmaceutical care skills inside the school" at the main line of five working processes on pharmacist job.

Through questionnaire investigating students' attitude, satisfaction, difficulty, gains, recognition about practical training as well as opinions and suggestions of course design, we found that: most students hold positive attitude which is helpful to carry out the practical training smoothly; for satisfaction, students are most satisfied with the design of practical training; for difficulty, they think that scenario simulation is the most difficult part; expression and communication are not only the most difficult part in the practical training but most rewarding one. Through statistics of gender differences, we find that girls are more satisfied than boys and there are no other obvious differences.

\section{The Design of the Teaching Model of the Practical Training for Pharmaceutical Care Skills inside the School}

Pharmaceutical service is that pharmacy workers use professional knowledge of pharmacy and tools to provide all kinds of services related to drug use (including drug selection, application of knowledge and information etc.) making patients get safe, effective, economic, legal drug treatment.

Many health care personnel have clearly known that the cost brought by problems related to drugs is far more than the price of drugs themselves which indirectly causes huge loss [2].Through pharmaceutical service, pharmacy workers provide better drug treatment plan for the public and meet their basic essential health care from the angle of pharmacoeconomics on the basis of guaranteeing medication safety and drug efficacy. Higher vocational education is professional 
capacity oriented. To a lot of students who are engaged in drug managing industry, "Pharmaceutical care skill" is an essential skill. It embodies the employee's basic occupation quality and professional knowledge. Aiming at the target of cultivating students' "pharmaceutical service skill" and embodying school's philosophy that is "professional capacity oriented, work program driven", we follow the main line that is five working processes on pharmacist job such as "basic medical examination technology" "counterfeit or substandard medicines identification" "sale without a prescription" "prescription checking" "Traditional Chinese medicine prescription distribution" and based on those course theories such as pharmacology, pharmaceutical products, traditional Chinese pharmacy, drug marketing to implement practical training teaching inside the school.

\section{The Implementation of Practical Training Teaching inside the School for Pharmaceutical Care Skill}

The training mainly adopts the task-driven teaching method and divides the contents of the training into six modules. They are basic medical examination, counterfeit or substandard medicines identification, building drug instruction archives, prescription checking, sale without a prescription, traditional Chinese medicine prescription distribution. Every module will set different task target which work in a group of one to three people and will be finished in one to three days. The teachers evaluate and score according to students' completion of the task. The score will constitutes a certain proportion in scholarship assessment which encourages students fulfilling the task seriously.

\section{A. Basic medical examination}

Medical examination is one of basic skills and common works in the pharmaceutical care job in which checking blood pressure, blood sugar and heart rate is used most frequently. What's more, it has low requirement to equipment and has been used widely. It is a main objective for practical training module that mastering technologies of basic medical examination and ensure accuracy of the checking result.

The module require students to apply convenient instruments and devices in measuring blood pressure, blood sugar, heart rate, body temperature and vision as well as the reagent to check ABO blood group system. Teachers can evaluate students and score according to the standard degree of actions in the process of checkup and the accuracy of the result.

\section{B. Identifying counterfeitor substandard medicines}

Counterfeit or substandard medicines appear more frequently, wide in range, quick circulation, changeable in making and selling approach as well as forms. It is a requisite pharmaceutical care skill for professional students studying pharmaceutical trading and management to own the skill of identifying counterfeit or substandard medicines.

For the need of practical training for pharmaceutical care skills, we cooperate with one famous drug sale chain enterprise building simulated pharmacy training room that stays the same with the real pharmacy in appearance, facility, decoration and lay out. Packages and directions of medicines in the pharmacy are all provided by cooperative enterprise. First, the teacher explains the difference of appearance, property, smell and fluorescence between real and counterfeit medicine. Besides, material objects will be demonstrated. Then students choose twenty real and counterfeit medicines randomly to identify them and fill in the training report. The teacher can evaluate students and score based on the report that shows mastery condition of real and counterfeit medicines. The template is used to format your paper and style the text. All margins, column widths, line spaces, and text fonts are prescribed; please do not alter them. You may note peculiarities. For example, the head margin in this template measures proportionately more than is customary. This measurement and others are deliberate, using specifications that anticipate your paper as one part of the entire proceedings, and not as an independent document. Please do not revise any of the current designations.

\section{Building files of drug instruction}

Drug instruction is a legal document specifying important information. It is a basis for a doctor to prescribe for drug therapy and an important reference when patients take medicines. The training in 
this module focuses on tasks of collecting drug instructions about internal medicine, dermatology, ophthalmology and otorhinolaryngology, gynecology, surgery and other common diseases. Take ophthalmology and otorhinolaryngology as an example, first make corresponding diseases such as rhinitis, conjunctivitis and otitis media etc. be classification indicators then fill in drug instructions correspondingly finally finish sorting out all the instructions and their binding in terms of treatment objects.

In the process of building files, students can master each name of drugs, pharmacological effect, clinical use, adverse reaction, incompatibility and collect first-hand information for training module. Teachers can evaluate students and score based on these files sorted by students.

\section{Prescription checking}

Prescription checking is an important guaranty for rational drug use and the premise for patients using drugs effectively and safely. Medicine untoward reaction is predictable. Through rational use, we can avoid the harm caused by untoward reaction to great extent.

We do prescription checking training in the simulated pharmacy in the form of scenario simulation and divide students into three groups acting as a doctor, patient and pharmacist separately. The student acting as a doctor prescribes, the one as a patient gives the prescription to the student acting as a pharmacist who will check the prescription and dispense drugs. The contents of checking are mainly before the prescription, text, rational drug use, repeated drug use and incompatibility etc. If these problems arise, the pharmacist acted by the student will analyze and explains the reason. The teacher can evaluate students and score according to their performance in the scenario simulation.

\section{E. Sale without a prescription}

Nonprescription drug refers to those drugs that can be sold without a prescription given by a doctor or other medical professionals after National Health Administrative Department requires or approves on the premise of safe drug use. The meaning of setting nonprescription drug is no need for medical advice and supplying quick effective releasing method which can ease the pressure of medical service.

In this module, role-playing is the main teaching method. First divide students into groups and then let students themselves design the scenario of "asking the disease and selling the drug". One group of students play the role of patient, the other student acts as a pharmacist. According to their own design, they simulate the process of service and sale in "asking the disease and selling the drug" between the pharmacist and patient. All the students must change their role after the end of scenario simulation and go on the next simulation. The teacher can evaluate students and score in terms of their comprehensive performance.

\section{F. Traditional Chinese medicine (TCM) prescription distribution}

Traditional Chinese medicine prescription distribution is the operating process of TCM pieces qualified in processing dispensing to oral or external medication for patients with the feature of temporary prescription deployment. The desired effect of TCM prescription depends on TCM producing area, breeds, quality, dosage in prescription distribution and what the process is whether or not dispensing correctly. So professionals who engaged in prescription checking of TCM pieces and distribution have to possess skilled theory basis and practical skills of TCM.

According to common problems and matters needing attention in the process of TCM prescription distribution, we design the module into two parts. The first part is checking the prescription including the date of the prescription and all the basic information about patients so that we can timely find whether the pregnancy-contraindicated drug, the overdosed problem, irrational drug use etc. exist. The second part is prescription distribution which strictly based on requirements of the prescription and must be correct in taste and dosage. After the dispensing, another student must check and proof. The teacher can evaluate students and score based on the specific performance in the process of checking and dispensing. 


\section{The Situation of Carrying out the Practical Training and Summary of Experience}

Through carrying out the teaching reform project "Practical Training of Pharmaceutical Service Skill inside the school" in majors of pharmaceutical trading and management, we find that the training result of independent pharmaceutical service skill is obvious relative to traditional course experiment. After investigating students' attitude, satisfaction, difficulty, gains, recognition about practical training as well as opinions and suggestions of course design, we summary the results as follows.

We distribute 212 questionnaires and acquire 212 back in which consist of 16 boys accounting for $17 \%$ of the total and 176 girls accounting for $83 \%$.For students' attitude to the training, $74.5 \%$ students choose "like it very much" which illustrates that students hold positive attitude toward practical training and is helpful to carry out the training smoothly. For the satisfaction about the training, they are most satisfied about the design of training project and time arrangement comes second. Students are less satisfied about the training conditions. So practical training teaching should focus on strengthen improvement in training conditions to increase students satisfaction in future. As for difficulty of the training, students think that course experiment training is more difficult among which "asking the disease and selling the drug" in scenario simulation part is most difficult for it mainly simulates the scenario of communication with patients which shows students must improve their skills of communicating and we will take into account increasing the proportion of this part and strengthen communicating training. In the statistics of students' gains, teamwork and expression as well as communication get highest score. Combining with our investigation about training difficulty, we find that expression and communication are not only the most difficult part but the most rewarding part. Through the statistics of gender difference, we find that girls are more satisfied than boys and there is no other difference. Therefore, teachers should gain in-depth insight into what factors lead to boys' low satisfaction degree and timely control boys' negative emotions caused by dissatisfaction with the training.

*Supported by the Educational Reform Foundation of Chongqing University of Education (NO. JG201124)

**Corresponding auther (E-mail: lazhuyu2@163.com)

\section{References}

[1] Li Wang,Ruiting Han,Yunqi Zhang,Chunyan Wan,Xiumei Guo, "The study on practical training of pharmacy service skills for pharmaceutical management major,"Liaoning HigherVocational Technical Institute J.,vol.12,Mar. 2010, pp. 59-60

[2] McDonough RP, Rovers JP, Currie JD, “Obstacles to the implementation of pharmaceutical care in the community setting,".J Am Pharm Assoc, vol. 38, Jan. 1998, pp. 87

[3] Yi Wang, Bin Liu, Yue'e Luo, "The study on practice course of vocational pharmacy major," China Foreign Medical Treatment, vol. 14, Jul. 2008, pp. 81-82

[4] Xuan Sheng, Yun Fang, "Study on Clinical Probation Model of Clinical Pharmacy for Undergraduate Students," Pharmaceutical Education, vol. 25, feb. 2009, pp. 40-42

[5] Guihua Yin, "Practice of the Application of Simulated Pharmacy,"ChinaPharmacy, vol. 23, Aug. 2012, pp. 765

[6] Xianliang Deng, "Significance and Prospects of Community Pharmacy Services," China Pharmacist, vol. 9, Oct. 2006, pp. 972-973 